\section{Coordination in organizations: A game-theoretic perspective}

\author{
Colin Camerer and Marc Knez
}

\subsection{Introduction}

Classic literature on organizations recognizes that the paramount function of an organization is the coordination of physical and human assets to produce a good or service (e.g., Barnard, 1938; Chisholm, 1989; Schein, 1985). Coordination in this early literature was defined broadly, as for example by Mooney (1947, p. 5): "Coordination therefore, is the orderly arrangement of group effort, to provide unity of action in the pursuit of a common purpose." Mooney argues further that coordination is the first principle of organization and that any other organizational principles "are simply principles through which coordination operates and thus becomes effective" (p. 5). The landmark work of Thompson (1967) distinguished kinds of interdependence that give rise to coordination problems and ways in which coordination might occur - for example, by standardization, planning, or mutual adjustment. Coordination also plays a central role in recent thinking about the economics of internal organization (Becker \& Murphy, 1992; Milgrom \& Roberts, 1992), the history of business organization (Lamoreaux \& Raff, 1995, esp. p. 5), core competencies in business strategy, mutualism and legitimation in organizational evolution, macroeconomics (Cooper \& John, 1988), and other fields.

The need for coordination arises if the organization's success depends on the decisions made by each of a group of actors, and the decisions interact in determining success. In the traditional sense, a coordination problem exists if achievement of a particular organizational goal requires that each actor select the appropriate action, and the goal is not fully achieved if all members of the group do not select goal-fulfilling actions.

We thank participants in seminars at the Chicago GSB Behavioral Science workshop, the UCLA Policy and Organization workshop, the 1995 Academy of Management meetings, Don Kleinmuntz, Roy Radner, and Zur Shapira for comments and ideas.
To illustrate coordination problems, it may help to first imagine an organization that does not require much coordination. Picture a room full of equally skilled workers who draw similar garment pieces from a central bin and sew them together. If the sewing is simple enough, then the "organization's" total output is just the sum of each worker's output, and coordination of workers' efforts is not important. Extending the example shows how likely it is that coordination really is important. If the garments differ in complexity and workers differ in skill, then assigning hard work to the best workers improves output, so some coordination of workers' garment choices is required. If work on a particular garment is spread over time, so that one worker adds additional stitching to a garment previously worked on by another (as on an assembly line), then workers' output speeds are clearly interdependent and coordination is again necessary. If certain workers like each other, and being physically located near their friends helps their productivity (or hinders it!), then coordinating where workers sit improves productivity.

Our chapter presents a game-theoretic perspective on coordination problems like these. It belongs in this book because choosing which action to take in a coordination game is a social decision; it requires people to think about what others will do (and also about social values, such as whether they care to maximize their own payoffs or the group's payoffs). In addition, we make a few comments about how decisions in coordination games may reflect heuristics visible in individual decision making.

The main goal of the chapter is to describe a class of coordination games, argue for their relevance to the study of organizational decision making, and describe findings from several experiments on such games. A secondary goal is to whet readers' appetites for broader application of game theory to the study of organizational behavior in the spirit of Murnighan (1994) and Gibbons (in press).

\subsection{Three kinds of impediments to coordination}

Broadly speaking, the literature on organizations has recognized three kinds of impediments to coordination. In each case, we describe the impediment, characterize it using a slightly different coordination game, and give an organizational example.

\subsubsection{Team decisions and matching games}

The organizational problem. One kind of impediment to coordination arises when group members all have the same preference rankings over the set of possible group outcomes (i.e., any action that leads to a higher payoff to one group member also leads to higher payoffs to all other members) but reaching the best outcome is not easy. A group like this is called a team (Marschak \& Radner, 1972). 
Coordination failures in teams are typically attributed to the complexity of multiperson interactions and to the fact that group members have different information or control different actions. For example, a firm may want to produce a single national-brand shoe, but five regional marketing directors all have different opinions (based on their local information) about which shoe will sell best. Their problem is how to aggregate information, not what to do afterward.

Analysis of team decision-making problems focuses on the derivation of optimal decision policies under alternative information structures. Although the theory of teams is interesting and important in its own right, from a behavioral perspective it is naturally limited because it assumes that team members all have the same goal. Radner's chapter in this book describes some important recent results on how to design team organizations to aggregate information optimally when information processing takes time and information depreciates over time.

The game. A (noncooperative) game involves a set of players, strategies those players can choose, consequences that result from each combination of strategies, utilities that express how players value the possible consequences, rules for which players move when and what players know when they move, and random choices by an exogeneous "nature" (which may include outside players who are uninterested in the outcome). A spate of recent books have made the basics of game theory accessible at many levels (e.g., Gibbons 1992); we will not dwell on details or definitions except when necessary.

The simplest expression of a team coordination problem is a matching game, shown in Figure 8.1. Two players, labeled person 1 and person 2, choose either $\mathrm{L}$ or $\mathrm{H}$ simultaneously. Each cell of the matrix shows the payoffs to the two players (in utilities) from each combination of choices; the first (second) number denotes person 1 (2) payoffs. For example, if both players choose $\mathrm{L}$, denoted $(\mathrm{L}, \mathrm{L})$, they each get 5 , and if both choose $\mathrm{H}$, they each get 10 . Figure 8.1 captures the most basic property of a team coordination problem because players agree that the outcome $(\mathrm{H}, \mathrm{H})$ is better than $(L, L)$.

Notice that the matching game captures the basic property of coordination we mentioned in the introduction because the player's payoffs are an interactive function of their choices: If they match choices they both do well, but if they mismatch they get nothing.

An example. Consider a luxury hotel that strives to provide a high quality of customer service by encouraging its staff to be attentive to customers' needs. Suppose that the hotel slightly prefers customers to check out by 1 P.M. rather than 2 P.M., but mainly worries that customers are not told two different checkout times by different employees (because customers take the confusion to be a sign of low-quality service, for example, or resent

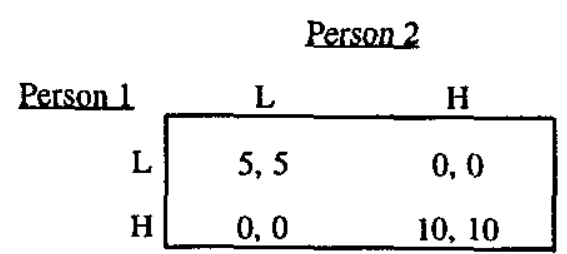

Figure 8.1. Matching game.

wasting more time finding out which time is correct). Now consider the game played by two employees who must tell a guest the checkout time. If they share the group's (hotel's) payoffs, their payoffs are like those in a matching game. The two employees would like to match the times they announce and prefer to both say 1 P.M., but their main concern is to avoid mismatching times.

Obviously, this coordination problem appears to be easily solved by instructing employees to announce a single checkout time. But problems may arise under many circumstances - for example when new employees arrive from other hotels with 2 P.M. checkout times. Now the old employees must guess whether new employees will remember to say 1 P.M. or will forgetfully say 2 P.M.; the old employees must guess what new employees will guess they will guess; and so on.

\subsubsection{Mixed-motive conflict, bargaining, and battle-of-the-sexes games}

The organizational problem. A second impediment to coordination arises when group members have different preferences about organizational outcomes (e.g., principal-agent conflicts). For example, many applications of negotiations to organizational behavior discuss the bargaining problem that arises between organization members (e.g., Neale \& Bazerman, 1991). The typical bargaining problem has a set of mutually agreeable possible solutions and an impasse or no-agreement point that is worse than any of the candidate solutions. Bargainers all prefer one of the solution points to reaching an impasse, but each bargainer prefers a different point. This mixed-motive situation creates a coordination problem because bargainers would like to agree on some solution rather than none, but there are many possible solutions.

Similarly, March and Simon (1958) and many others have stressed the importance of getting organization members to identify with organizational goals. Our discussion breaks "identification" into two different parts. In mixed-motive games the outcomes two players desire are not the same (though both desire to avoid some undesirable outcomes); hence there is no clear, single organizational goal both can identify with. In the risky coordination games we describe later, there is a clear, commonly desired outcome but players are not sure that others will risk striving for it. In these 
Person 2

\begin{tabular}{rcc} 
Person 1 & $L$ & $H$ \\
\cline { 2 - 3 } & $L$ & \multicolumn{1}{c}{$L$} \\
H 10,5 & 0,0 \\
0,0 & 5,10 \\
\hline
\end{tabular}

Figure 8.2. Battle-of-the-sexes game.

games, "identifying" the organizational goal means not knowing that a goal exists but believing that others will strive for it.

The game. A simple game known as battle of the sexes (BOS) captures this second impediment to coordination. Figure 8.2 shows payoffs in a BOS. Persons 1 and 2 both prefer matching to mismatching (and getting nothing). But person 1 would rather match on $(L, L)$ and get 10 , and person 2 would rather match on $(\mathrm{H}, \mathrm{H})$ and get 5 . In a sense, persons 1 and 2 are bargaining over whether to divide a total possible gain of 15 into $(10,5)$ or $(5,10)$ or to mismatch and get nothing.

An example. Returning to the hotel, consider two room service waiters standing in different parts of the kitchen as an order is finished, ready for delivery, and the cook signals for a waiter. Assume that both prefer to have the order delivered promptly (otherwise the customer's wrath will lead to substantial punishment for both of them), neither one wants to deliver it (or both $\mathrm{do}^{1}$ ), and if both rush over to grab the order, an argument ensues that slows the delivery and harms them both. Then the game they play is a BOS with strategies relabeled ( $\mathrm{L}$ corresponds to person 1 delivering, $\mathrm{H}$ to person 2 delivering). If they can communicate or have some shared organizational rule (see March's and Zhou's chapters in this book), like seniority or delivery rotation, the bargaining problem is probably easily solved. But if communication is difficult, no rule exists, and the stakes are high, a coordination failure could result.

\subsubsection{Risky coordination, and assurance games}

The organizational problem. A third impediment to coordination arises when group members have common preferences over outcomes but the best outcome requires a risky action that group members do not want to take unless others do. Organizational change is like this if it requires members to make investments in learning new techniques that they prefer to make if, and only if, others do too.

The game. Risky coordination can be captured in an assurance game, as in Figure 8.3 (also called stag hunt in game theory jargon). Suppose persons 1

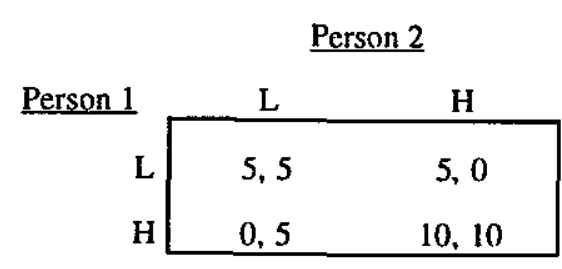

Figure 8.3. Assurance game.

and 2 can exert high $(\mathrm{H})$ or low $(\mathrm{L})$ effort. Low effort yields a certain 5 for the person exerting that low effort. High effort costs more, so choosing $\mathrm{H}$ alone yields 0 , but if both players choose $H$ they each earn 10 . (If $H_{i}=1$ when player $i$ chooses $H$, the payoff function for person 1 can be expressed as $5-5 \mathrm{H}_{1}+10 \mathrm{H}_{1} \mathrm{H}_{2}$, so the interaction or productive synergy between the effort choices of persons 1 and 2 are clear from the product term $\mathrm{H}_{1} \mathrm{H}_{2}$.)

The players' preferences are consistent because person 1 is better off selecting action $\mathrm{H}$ if player 2 also selects $\mathrm{H}$ and better off selecting $\mathrm{L}$ if 2 also selects L. But the interdependence of each player's actions is fundamental because person 1 is better off choosing $\mathrm{H}$ only if person 2 chooses $\mathrm{H}$ as well. Note that the assurance game is a form of matching because players want to match other players' choices. The difference is that the mismatch payoffs are not all zero (as in Figure 8.1 matching). Because the mismatch payoff from choosing $\mathrm{L}$ is 5 and the mismatch payoff from choosing $\mathrm{H}$ is 0 , $\mathrm{L}$ is less risky than $\mathrm{H}$ and might be chosen even though $(\mathrm{H}, \mathrm{H})$ is better.

An example. Back to the hotel. Suppose that a customer's total level of satisfaction is disproportionately affected by the minimum level of service she receives; if she has a bad experience with anyone on the hotel staff, her overall level of customer satisfaction is low. Moreover, suppose that the combination of intrinsic and extrinsic rewards implies that each employee prefers that customers receive the highest level of job satisfaction, but each employee does not want to exert extra effort toward this goal if the extra effort does not raise the customer's overall level of satisfaction. Under these assumptions, a hotel employee's decision to exert extra effort to increase a customer's level of satisfaction depends on his expectations concerning the minimum level of service that will be provided by the other hotel employees. If his expectations are low, then he does not want to risk providing high-quality service. Conversely, if his expectations are high, then he does not want to be the only one to upset the customer by providing low-quality service. High levels of customer satisfaction will be achieved only if each employee expects that a significant number of other employees will provide high-quality service.

Notice that prescribing a policy of high-quality service would work in a team theory framework (captured by the matching game), but in an assurance game it works only if employees believe others will adhere to the 
policy. Simply announcing the policy is not enough: It must be credible, widely believed, and so on.

\subsubsection{An aside on terminology: Equilibrium}

Up to now we have defined a coordination problem as a joint decisionmaking problem. This definition is useful for categorizing impediments to coordination, but it makes no predictions about how players will behave. The central predictive tool in simple games like these is the Nash equilibri$u m$, a set of strategies that are mutual best responses to one another. Notice that strategy is simply a fancy word for the choices players can make. An equilibrium is some predicted outcome of the game or set of strategies chosen by players.

To illustrate the Nash equilibrium concept, consider the assurance game in Figure 8.3. This game has two (pure-strategy) Nash equilibria - the low equilibrium $(\mathrm{L}, \mathrm{L})$ and the high equilibrium $(\mathrm{H}, \mathrm{H})$. The outcome $(\mathrm{L}, \mathrm{L})$ is a Nash equilibrium because if one player expects the other player to select $L$, then that player should also select $\mathrm{L}$. (The two $\mathrm{L}$ choices are mutual best responses.) The same is true for the outcome $(\mathrm{H}, \mathrm{H})$. If each player expects the other player to select $H$, then it is a best response to also select $H$. Note also that both players are better off in the $\mathrm{H}$ equilibrium, so we call $(\mathrm{H}, \mathrm{H})$ efficient and $(\mathrm{L}, \mathrm{L})$ inefficient.

The outcomes $(\mathrm{H}, \mathrm{L})$ and $(\mathrm{L}, \mathrm{H})$ are not Nash equilibria. For example, suppose player 1 expects player 2 to select $L$, and player 2 expects player 1 to select $H$. Then player 1 should select $L$ (not $H$ ), and player 2 should select $\mathrm{H}$ (not $\mathrm{L}$ ). The key difference is that in equilibrium, expectations are aligned with actions, whereas out of equilibrium they are not. This notion of equilibrium is not very different from the same term used by Kurt Lewin, who saw equilibria as the result of conflicting social forces pushing in various directions.

Now that we have explained what an equilibrium is, we can use the BOS in Figure 8.2 to illustrate why getting game theory right is important. In addition to the equilibria $(\mathrm{L}, \mathrm{L})$ and $(\mathrm{H}, \mathrm{H})$ in $\mathrm{BOS}$, there is a third mixed strategy equilibrium in which both players choose random mixtures, playing $\mathrm{L}$ with two-thirds probability and $\mathrm{H}$ with one-third probability. (Those mixtures by one player make the other player indifferent between playing $\mathrm{L}$ and $\mathrm{H}$, so the mixed strategies are weak best responses to each other.) The mixed strategies yield an expected payoff of $10(2 / 9)+5(2 / 9)=30 / 9$, or 3.33 to each player. Notice that two players using this strategy will have a joint payoff of $(3.33,3.33)$, which is lower for both of them than either the $(L, L)$ payoff of $(10,5)$ or the $(\mathrm{H}, \mathrm{L})$ payoff of $(5,10)$. But $(3 \cdot 33,3.33)$ is an equilibrium because players choosing it are too stubborn, put loosely, to switch unilaterally to something better. Therefore, as in Figures 8.1 and 8.3, the players could choose a pair of strategies that are best responses, and hence a (Nash) equilibrium, but that are inefficient. A critic who then concludes that players are not rational, or not obeying game theory, misunderstands the game theory.

The assurance game illustrates the two key features of a coordination game: The game has multiple Nash equilibria, and the set of equilibria are Pareto-rankable. Pareto-rankable simply means that for any two Nash equilibria in the game, one equilibrium is better for both players than the other. Notice that this game-theoretic definition is narrower than the traditional definition we gave at the start of this chapter. Most important, the traditional definition includes a situation in which a Pareto-optimal outcome is not a Nash equilibrium (hence, players have no individual incentive to work toward the group goal) as a kind of coordination problem.

\subsection{The subtle relation between cooperation and coordination}

The use of simple games to study organizational phenomena is not new. However, such research has focused largely on the $N$-player prisoners' dilemma (PD) games (or social dilemmas). Although the application of the $\mathrm{N}$-player PD has taught us about the conditions under which cooperation may be observed in an organization, we argue next that very few true PDs exist in organizational life and that the essential property of most apparent PDs is the coordination problem embedded in them.

\subsubsection{Prisoners' dilemma game}

Coordination failure occurs in the assurance game (Figure 8.3) because each player's expectations are not aligned on the $(\mathrm{H}, \mathrm{H})$ outcome. If player 1 expects player 2 to select $L$, then her optimal action is to also select $L$, and likewise for player 2. This coordination problem is distinct from a problem of cooperation, where achieving optimal group outcomes requires that individual members of the group suboptimize their individual payoffs.

In Figure 8.4 we alter the assurance game in Figure 8.3 to create a version of the well-known PD. The payoffs are identical to those of the assurance game except for the payoff to a player if he or she selects D (defect) and the other player selects $\mathrm{C}$ (cooperate) (known as the temptation payoff in the PD literature). This payoff has been raised from 5 to 12 . So, for example, if player 1 selects $D$ and player 2 selects $C$, then player 1 receives 12 , his or her highest payoff. This changes the game dramatically. Because neither player has an incentive to select the high-quality action, the low-quality outcome will occur, resulting in the lowest possible total payoffs. The only way the players will be able to coordinate their actions on the high-quality outcome is if they both forego maximizing their individual payoffs in the interest of maximizing their joint payoff.

Note that PD has a unique equilibrium, so it does not represent an impediment to coordination in the game-theoretic sense. However, it does characterize a situation in which players' choices will lead to inefficiency. 


\section{Person 2}

Person 1 D C

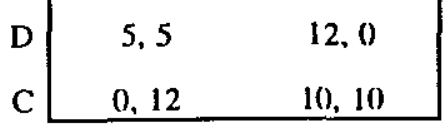

Figure 8.4. Prisoners' dilemma.

\subsubsection{How to tell PD and coordination games apart}

The central feature of a PD is that players have dominant strategies that, when played by everyone, lead to an inefficient outcome that everyone dislikes. The central feature of coordination, as we have defined it, is that players do not have dominant strategies because they prefer to reciprocate (or match) the strategy that produces the efficient outcome; but they also prefer to reciprocate an inefficient strategy. Hence, the crucial difference between the two kinds of games is the answer to a simple question: Do players prefer to reciprocate the high-outcome strategy? If not, the game is PD. If so, the game is coordination.

\subsubsection{Are most apparent PDs really coordination games?}

We argue that under three common conditions, games classified as PDs are essentially coordination games because players would like to reciprocate cooperation.

1. In many apparent PDs, players can earn more money by defecting when another player cooperates (so defection is a dominant strategy), but they reciprocate cooperation instead. For example, about half of the subjects cooperate in one-shot experimental PDs (e.g., Ledyard, 1995), and players who expect cooperation tend to cooperate more frequently than those who expect defection. These players appear to care about something besides maximizing their own monetary payoffs; they prefer to reciprocate "nice" behavior (sacrificing money to enrich another person) with niceness (Rabin, 1993; Sally 1995). The players appear to have an internal representation of the game as a problem of coordinating levels of niceness or cooperativeness.

2. In many apparent PDs, there is a superadditive synergy or complementarity if both players cooperate. (Think of members of an R\&D team who hold different pieces of a scientific puzzle and whose pieces are worth much less until they are combined. Step-level or threshold public-good games have this property too; see Rapoport, 1987. Games with participation or network externalities or bandwagon effects are coordination games too.) Conversely, it may be easy to identify players who defect and exclude them from sharing gains from cooperation by others. For example, team mem- bers can report whether others contributed or not, and supervisors use these self-reports to allocate rewards. If synergies from mutual cooperation are large enough or exclusion of defectors is easy enough, then players who reciprocate cooperation will earn more money than defectors. Then the game is a coordination game, not a PD.

3. Suppose PD is infinitely repeated, with no apparent end in sight, players are not too impatient (i.e., they have a low discount rate), and they can change their behavior in any one period to respond to what others did before. Then a well-known folk theorem in game theory implies that reciprocating cooperation is one money-maximizing strategy (if failing to do so triggers tit-for-tat punishment in later periods). The repeated PD is thus a coordination game; players need to coordinate on when to defect - preferably never!

These arguments show that an apparent PD is essentially a coordination game unless all of the following conditions are met: (1) the players don't care whether others are nice or not, (2) there are low synergies or ability to punish defectors, and (3) there is either a limited time horizon, impatient players, or forgetful players. It is easy to think of unorganized social situations, like looting during catastrophes or overusing a common resource pool like a field, river, or lake, which may satisfy all three criteria and hence are pure PDs. But because organizations usually have long time horizons and can observe members, who know each other and may be friends, it is hard to think of any organizational examples that satisfy all three of these criteria.

For example, some people have written about organizations as "common pool resource dilemmas" in which players can take resources from a common pool that reproduces or replenishes itself at a natural rate (e.g., Kramer, 1990; Mannix \& White, 1992; see also Kidwell \& Bennett, 1993). In most organizations, taking resources is largely constrained by organizational rules. Putting that obvious criticism aside, if the organization is longlived, then there are equilibria in which players take patiently from the common pool and an inefficient equilibrium in which everyone takes everything immediately, if they can. Hence the core problem in such a dilemma is coordinating on the good (slow consumption) equilibrium.

An interesting exception may be organizations near bankruptcy or undergoing downsizing, in which workers may become angry at employers and time horizons shrink. Otherwise, we hope to have shifted the burden of proof to those scholars who study PDs, to show precisely why the key feature of any situation they model is PD (dominant strategies yielding Pareto-inefficiency) rather than coordination.

\subsubsection{Are coordination games more common than PDs?}

There are at least two mathematical ways in which we can compare how common coordination and PD games are. First, Rapoport and Guyer (1976) 
classified all two-strategy, two-player $(2 \times 2)$ games into one of 78 types. Only one is a PD and several are coordination games in one of the three categories illustrated by our hotel examples. Seen this way, PDs are actually quite rare and coordination games are much more common.

Second, Stanford (1995) extends several remarkable theorems on how many pure-strategy equilibria exist in games where players' payoffs are randomly and independently determined. He shows that as the number of strategies grows, the chance that a game has exactly $k$ pure-strategy equilibria approaches $.37 / k$ !. This simple expression implies that the frequency of single-equilibrium games $(k=1)$ is about $37 \%$ as the number of strategies expand. But PDs are a special type of single-equilibrium game: They require all players to have dominated strategies that lead to a Paretoinefficient outcome. (As the number of strategies expands, the chance that a game with random payoffs has this special PD property goes toward zero.) Hence, PDs are only a small fraction of the $37 \%$ of single-equilibrium games.

At the same time, one can show that games with two or more equilibria occur randomly $26 \%$ of the time; all of these games represent coordination problems. Therefore, as the number of strategies grows large, there is a strict mathematical sense in which coordination problems become more and more (relatively) frequent than PDs (assuming payoffs are randomly chosen). And because enlarging the number of strategies makes games more realistic, we can argue that with a realistic view of the world, PD is a much less likely representation of an organizational problem than coordination is.

\subsubsection{Example: The employment relationship as a coordination problem}

Several different literatures focus on the underlying structure of the employment relationship. An emerging literature on organizational citizenship behavior posits that organizationally beneficial behavior exists within organizations that is not driven by formal obligations dictated by the employment contract (Organ, 1988). Work on psychological contracting focuses on workers' and managers' perceptions of the unwritten terms of their employment contract (see Rousseau \& Parks, 1992). The analogous question in economics is how contracting parties behave under an implicit contract, or when unspecified contingencies occur. The economists' answer is usually pessimistic: Parties try to exploit one another when something not explicitly covered in their contract occurs. An alternative answer some economists have advanced is that happy workers repay "gifts" given to them by firms in the form of higher-than-market-clearing wages (beneficial nonwage gifts work equally well) with unmeasured effort (Akerlof \& Yellen, 1990).

From the perspective of game theory, all of these literatures describe the same fundamental phenomenon. In workplaces there are (at least) two sorts of equilibria: (1) Firms treat workers well and workers reciprocate by providing more effort than is required, or (2) firms and workers strike an emotionally neutral bargain to exchange money for clearly specified work; when something unforeseen occurs, neither side gives anything extra. If outcome (1) is an equilibrium, because workers acquire sympathy, affection, or loyalty, for their firm, then the game is one of coordination, not cooperation. Workers and employers are trying to coordinate on whether to behave nicely or not.

\subsection{Uses (and misuses) of game theory in studying organizations}

So far we have discussed kinds of coordination problems in firms, simple games that capture the features of these problems, and have argued that coordination rather than PD may be the kind of game most common in organizational life. Before proceeding, we offer a few comments about why many studies of organizational behavior have been reluctant to incorporate even simple aspects of game theory (beyond PD). An important barrier to thinking game-theoretically may be a misunderstanding of what game theory is good for and is meant to do.

\subsubsection{What is game theory good for?}

Game theory can be separated into two distinct parts: (1) a library of games as a system for classifying social situations and (2) a body of mathematical knowledge about how idealized players with varying degrees of rationality would actually play (equilibrium analysis).

The usefulness of games as a classification system (Aumann, 1985) is largely independent of whether the mathematics in part (2) is useful, nonsensical, empirically wrong, or whatever. For example, in the discussion so far, we have not leaned heavily on the idea of equilibrium or discussed the rationality of players (beyond simple utility maximization, which in these examples simply means picking the highest of three numbers). Our claim is that merely describing three kinds of coordination problems in gametheoretic terms provides a parsimonious, clear language that can help classify them. Furthermore, carefully distinguishing PD from coordination, in the previous section, makes it clear that very few organizational situations are pure PDs, and most have elements of coordination. Thus, even without doing any equilibrium analysis or predicting how people will play these games, simply using the games as a classification system can be of some use.

An analogy to biology may help illustrate our point. Biologists have produced careful classifications of organisms, into categories of varying depth - warm- and cold-blooded mammals, birds, plants, and so on. Each category is precisely defined by a small set of features (birds have feathers, fly, and lay eggs), and some exceptions are noted (penguins). Biologists 
also study the deepest workings of barely observable features of organisms, like DNA, genes, and neurons. But the scientific validity of the latter work has little to do with the usefulness of the former. Birdwatchers will find species classifications extremely useful even if their understanding of the genetic bases of diseases is incomplete or wrong.

\subsubsection{What is equilibrium analysis good for?}

The mathematical ideas in game theory about how rational players might play (in equilibrium) have come under reasonable attack from philosophers, psychologists, experimentalists - and many game theorists - as exaggerated descriptions of how normally intelligent people would behave (e.g., Zajac \& Bazerman, 1991). Virtually all game theorists now concede this point. In response, current research generally takes equilibria derived from mathematical reasoning as possible limiting points to which players might converge in repeated play and asks whether simple (boundedly rational), adaptive decision rules or evolutionary dynamics will lead mathematically to these equilibria or to others. The criticism that equilibrium analysis is irrelevant because people aren't smart enough to figure out the equilibria misses the point of the adaptive and evolutionary analyses.

\subsubsection{Games are mental models}

Game theory is usually silent on "where" a game exists. Because games are written carefully in matrices (like Figures 8.1 to 8.4), and sometimes in more complicated trees, the immediate image is something like a scoreboard at which all the players look, showing a payoff matrix. This image is misleading.

Instead, consider a team of basketball players in a large arena, where the scoreboard hangs above their heads so that they can't see it as they play. "Where" is the score? It is sensible to say that the score exists both on the scoreboard above the players (where fans can see it) and also in the players' heads as they play.

Similarly, it is sensible to think of games as internal representations, or mental models, which exist entirely in the heads of players. The games we write down and discuss in this chapter are like the score on the scoreboard above the basketball players' heads. The assurance game in Figure 8.3, for example, is our understanding of the most basic features of how two organizational members think about the consequences of their choices.

The mental model interpretation of games raises many new questions: Do players have the same mental models? How are mental models constructed and revised? When players are given written models, how do they create mental models from them? (How oversimplified are their models? See Neale and Bazerman, 1991.) These questions are novel for game theory because generally the game-theoretic action begins after a game is posed and becomes ripe for equilibrium analysis. But addressing them could prove a very important application of psychology and organization studies to empirical game theory. Porac, Thomas, and Emme's (1987) study of perceived competition among businesses is an interesting start.

\subsubsection{Why are researchers so fascinated by PD?}

Echoing Murnighan (1994) and Gibbons (in press), an underlying theme of our chapter is that organizational researchers should consider a wider variety of games than PD. This raises a natural question: Why is PD so popular among so many scholars? Besides being studied by various types of organization researchers, PDs are widely studied by social psychologists, political scientists, biologists, and many others.

We think some of the popularity of PD arises from a simple combination of an error in logic and ignorance of other kinds of games. In theory, players engaging in a PD or social dilemma will choose inefficiently. (That is, individually rational players make choices that make everyone worse off.) Because PD implies inefficiency, organizational researchers looking for a game-theoretic model of how conflict between personal and group goals results in organizational inefficiency might instinctively think of PD as if it were the right model of individual-group conflict. This is simply wrong because many other interesting games predict possible inefficiencies and may be better models for organizational phenomena than PD.

For example, in the coordination games we describe, efficient outcomes and inefficient outcomes are possible. Groups or firms can get stuck in an equilibrium nobody likes because they cannot coordinate a simultaneous switch to a better equilibrium (and players will voluntarily switch only if they think others will). This simple feature seems to characterize problems of "dinosaur" firms (like Sears and GM) at least as well as PD does (see also Rumelt, 1995, esp. pp. 115-117). It can also account for path dependencies, the tyranny of the past, the extreme sensitivity of equilibrium results to initial conditions, and other features commonly associated with organizational paradox. In Knez and Camerer (1994) we draw the analogy between norms or beliefs in coordination games and intangible expectational assets, which are one kind of resource described in popular resource-based views of differential firm success in business strategy research. Notice that a history of coordination on an inefficient equilibrium is like an expectational liability and, like a bad reputation, it cannot be easily disposed of.

Another class of games that often exhibit inefficiencies are games with information asymmetries. Gibbons (in press) argues cogently that games of this sort may serve as sharp models of many sorts of organizational behavior that appear perverse. In these games, inefficiencies typically result because players must take inefficient actions to convey their information credibly (or "signal") to others. For example, the current game-theoretic theory of strikes is that labor or management strikes in order to signal 
private information credibly about their own reservation wages to the other side (Kennan \& Wilson, 1990). Other papers model inefficiencies that arise from the "herd behavior" of rational corporate managers. For example, in Scharfstein and Stein (1990), managers will sometimes choose to forego unusual, high-profit projects and instead follow the herd, mimicking what other managers do, to avoid the risk of being thought of as bad managers. Kanodia, Bushman, and Dickhaut (1989) argue similarly that escalation to organizational commitment may result from managers' refusal to abandon projects to protect their reputations. Prendergast (1993) builds a theory of "yes men" around the idea that subjective evaluations of workers by superiors are necessary to help an organization decide who to promote, but this evaluation process naturally gives workers too strong an incentive to please their bosses.

We do not believe that game-theoretic models like these are definitive explanations for inefficient organizational practices. Indeed, these rationalizations usually compete directly with other behavioral explanations that are widely accepted by decision researchers. But such models create sharp competition between explanations based on incomplete information and those based on bounded rationality, and clarify what sort of data would support each explanation in an empirical competition that constitutes the logical next step.

\subsection{Coordination and organizational expectations}

The application of simple coordination games to organizational coordination problems focuses attention on mechanisms that transform expectations rather than mechanisms that transform preferences. We will refer to such expectations as organizational expectations. Coordination is achieved through organizational expectations because all members share a common expectation of how all the other members will behave. Building on the chapters of March and Zhou (this book), organizational expectations support organizational rules (or norms) that define the actions a member should take (or not take) in a particular situation, and result in the coordination and control of organizational activities.

Until recently, economists have had little to say about organizational expectations. Such issues had been contained in the "black box" of organizational processes that economists found convenient to ignore. However, the extensive introduction of noncooperative game theory into economics starting in the late 1970s and continuing today has provided economists with the analytic machinery to begin addressing this topic.

Game theory allows us to be precise about the structure of organizational expectations. Simplifying a bit, what is required is that each member's belief about the other member's intention to follow a particular rule is mutually understood. For example, in the assurance game, the rule "select the action associated with the most efficient outcome" (the efficiency rule for short) selects the Pareto-efficient outcome $(\mathrm{H}, \mathrm{H})$. In order for the efficiency rule to be followed, player 1 must believe that player 2 expects him (player 1) to follow the rule, and likewise player 2 believes that player 1 expects him (player 2) to follow the rule. In game theory this is known as the mutual knowledge condition and is a necessary condition for the existence of a Nash equilibrium. $^{2}$

The mutual knowledge condition merely formalizes the notion that in order for a rule of behavior to be followed, there must exist mutually reinforcing expectations between the players that the rule will be followed. Since mutual knowledge is a necessary condition for a Nash equilibrium, we can study organizational expectations by studying the selection of Nash equilibria. Unfortunately, game theory does not provide us with a strong theory that predicts which equilibria will be selected in coordination games. Instead, we are left with less satisfying focal principles (Schelling, 1960). A focal principle posits that certain deductive properties of the game being played will create mutually consistent beliefs among its players about how others will play the game. The most well-studied focal principle is payoff dominance (Harsanyi \& Selten, 1988). Under payoff dominance, if a unique Pareto-efficient equilibrium exists, then it will be selected in the interest of efficiency. ${ }^{3}$ That is, players will intuit that all other players will select the Pareto-efficient strategy because they also believe that everyone else will do the same. Pareto dominance is simply a fancy name for the efficiency rule discussed earlier.

Selection principles such as Pareto dominance are predictions about how players intuit rules of behavior from the mere structure of payoffs in the game. Any additional information about how other players in the game will behave, through either direct or third-party communication, is treated separately. Although game theorists and experimental economists who study equilibrium selection in coordination games do not normally address the more specific issue of organizational expectations, we argue that it provides a fruitful research paradigm for studying this issue.

Up to now, most of the research on equilibrium selection in coordination games has focused on how the structure of coordination games affects equilibrium selection. Loosely put, a game's structure is described by its payoffs, the number of players, and the set of actions available to each player. Specifically, researchers ask: Does the structure of a particular coordination game provide players with enough information to intuit the mutual knowledge condition underlying a well-specified rule of behavior (such as the efficiency rule)? Normally, the following baseline conditions are created to answer this question experimentally: (1) the structure of the game (payoffs, number of players, actions) is common knowledge and (2) players are not able to communicate with each other, nor do they know the identity of the other players (no possibility of repeated interaction). The 
outcome in the baseline condition (e.g., the efficient equilibrium versus the inefficient equilibrium in the assurance game) tells us whether or not more formal forms of communication are required to induce mutual knowledge.

In the following section, we highlight recent experimental work in this area. As we proceed, the experimental results reported involve richer hypotheses that begin to shed light on the issue of organizational expectations.

\subsection{Experimental results on coordination games}

Several recent experiments study how subjects play coordination games. In this section, we describe previous findings that represent initial steps in understanding the game-theoretic structure of organizational expectations. After describing the results, we make some remarks about experimental methods and how psychological experiments might differ in style from the ones we describe.

\subsubsection{Results on two-player assurance games with and without "cheaptalk"}

Cooper, DeJong, Forsythe, and Ross (1992) examine behavior in a $2 \times 2$ "assurance" coordination game shown in Figure 8.5. If subjects choose $\mathrm{L}$, they earn $\$ .80$ for sure. If they choose $H$, they earn nothing if others choose $\mathrm{L}$ and $\$ 1$ if others also choose $\mathrm{H}$. Hence, choosing $\mathrm{L}$ is an equilibrium. Choosing $\mathrm{H}$ is an equilibrium also - which yields $\$ 1$ points for each player - but it is riskier because it pays nothing if the other players choose $\mathrm{L}$. The authors' subjects played the one-shot assurance game 11 times with different players. Players did not know the identity of the players they were paired with, nor did they know the history of decisions other than in their own previous games.

Out of a total of 165 subject pairs, $160(97 \%)$ played the inefficient equilibrium $(L, L)$. The remaining five pairs played disequilibrium outcomes $(\mathrm{L}, \mathrm{H})$ or $(\mathrm{H}, \mathrm{L})$. Notice that even though $(\mathrm{H}, \mathrm{H})$ is an equilibrium, players never reached it. Choosing $\mathrm{H}$ maximizes the expected payoff only if the probability that one's partner chooses $\mathrm{H}$ is above $80 \%$. This required level of assurance seems to be too high.

Cooper et al. $(1992,1994)$ also studied the impact of one-way and twoway communication on assurance and subsequent choices. Under one-way communication, only one player sends a message announcing the action she intends to select. Subjects are not required to choose the action they announced (in game theory this nonbinding preplay communication is called cheap talk). Under one-way communication, most players $(87 \%)$ said they would play $\mathrm{H}$. (All data we report are from the last 11 of 22 periods.) Then 88 of the 165 subject pairs $(53 \%)$ played the efficient equilibrium $(\mathrm{H}, \mathrm{H}), 51$ pairs $(31 \%)$ played disequilibrium outcomes, and the remaining

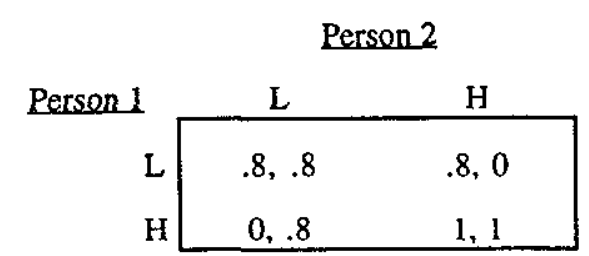

Figure 8.5. Assurance game payoffs (in dollars). (From Cooper et al., 1992)

$16 \%$ played the inefficient outcome $(\mathrm{L}, \mathrm{L})$. The problem was that many players who received the $\mathrm{H}$ message $(24 \%)$ weren't willing to bet that the message sender would follow through and chose the safe L instead. Indeed, many of those who sent $\mathrm{H}$ did not choose $\mathrm{H}$ subsequently $(20 \%)$. Hence, although one-way communication raises the percentage of $(\mathrm{H}, \mathrm{H})$ play from virtually none to about half, it does not fully solve the coordination problem.

Under two-way communication both players simultaneously send messages. Then players always announced they would $\mathrm{H}$, and 150 of the 165 subject pairs $(90 \%)$ did play the efficient $(\mathrm{H}, \mathrm{H})$ equilibrium. Two-way communication almost fully resolves the coordination problem in the assurance game.

\subsubsection{Basic results on the weakest-link game}

The weakest-link (or minimum-action) game is a many-player version of the assurance game that captures the gist of any situation in which a group or organizational goal is disproportionately affected by the lowest quality of each individual's inputs. ${ }^{4}$ Figure 8.6 provides a matrix-form example of the weakest-link game in which players choose numbers ${ }^{5} 1-7$. The figure shows the payoffs to a subject who chooses a Row action when the minimum action chosen by any subject in a group (including the row player) is shown in Column. For example, suppose there are three players, A, B, and $C$, and player A selects a 5 , player B selects a 4 , and player C selects a 3 . The minimum action selected is 3 ; hence, player $A$ receives $\$ .70$, player $B$ receives $\$ .80$, and player $C$ receives $\$ .90$. In this example, player A "loses" $\$ .20$ by selecting an action two increments above the minimum action selected. Each player wants to select exactly the minimum of the other players, and everyone wants the minimum to be as high as possible. But selecting high actions is risky because other players may select low actions. The assurance game is a two-person weakest-link game, and the payoffs in Figure 8.3 provide a way to extend the game to more players.

The customer satisfaction problem described earlier is an example of a weakest-link game. Assume that a customer's level of satisfaction with hotel service is determined by the lowest quality of service she receives. Then the weakest link in the chain of customer service is most important. 
SMALLEST VALUE OF X CHOSEN

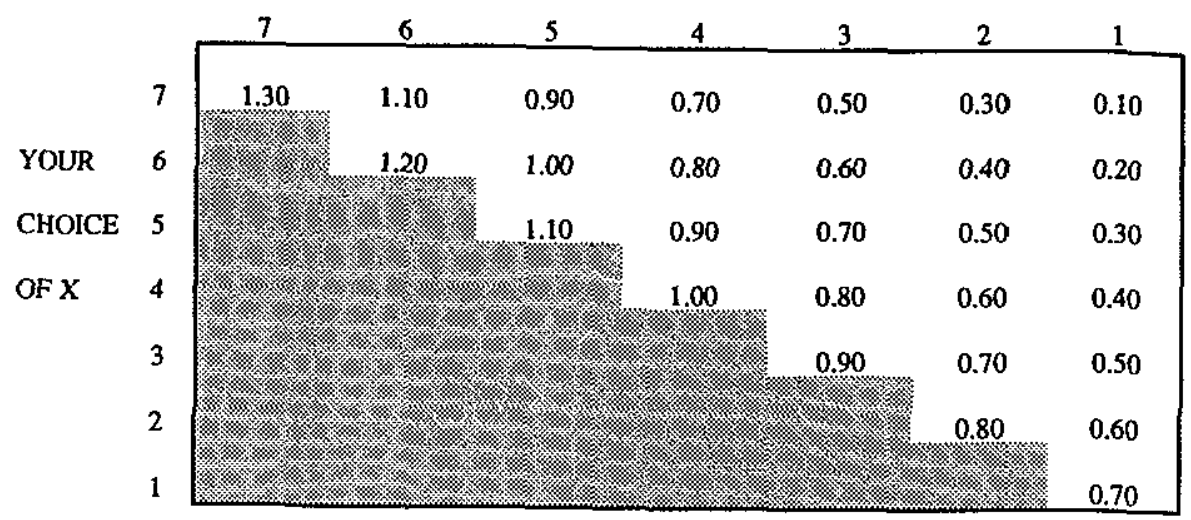

Figure 8.6. Weakest-link game.

Other organizational examples include (1) manufacturing a sensitive product, which is very likely to fail if any single part fails (some food and chemical production requires strict adherence to a "recipe" and very pure inputs; one bad ingredient ruins the whole batch); (2) production of safety in high-reliability organizations, which fail if a single failure occurs; (3) keeping a secret (or not repeating an organizational rumor), assuming that one or more leaks are equally harmful and assuming that everyone prefers to keep the secret only if everyone else will too; and (4) games of timing in which a project cannot be completed until all the parts are complete, such as assembling a report or prospectus or producing a book or special issue like this one (which can't be published until all chapters are in).

In all these cases, if poor quality of specific inputs is difficult to identify, and if participants dislike putting in high-quality inputs but share in an improved group output if everyone puts in high quality, then the weakestlink game provides a crisp description of an incentive problem that does not depend on the existence of a social dilemma. Inefficient behavior is created by the mere expectation that there is at least one weak link in the chain rather than by the incentive to free-ride if others are strong links.

Van Huyck, Battalio, and Beil (1990) (hereafter VBB) were the first to study behavior in the weakest-link game. In their experiments, roughly 15 undergraduate subjects played the game 10 times for the dollar payoffs shown in Figure 8.3. After each period of play the minimum action was publicly announced.

In all seven of their experimental replications, the number 1 was the minimum action selected after 10 periods of play, and roughly $75-90 \%$ of the subjects selected a 1 in the 10 th period of play (see Fig. 8.7). Hence, not only do large numbers of players find it difficult to play the weakest-link game efficiently, they tend to play the most inefficient equilibrium.

\begin{tabular}{|c|ccc|ccc|}
\hline & \multicolumn{2}{|c|}{ 3-player games (KC, 1995) } & \multicolumn{4}{|c}{ 14-16 player games (VBB, 1990) } \\
\hline & Actions & Minima & Minima & Actions & Minima & Minima \\
Actions & period 1 & period 1 & period 5 & period 1 & period 1 & period 5 \\
\hline 1 & $8(.13)$ & 5 & 6 & $2(.02)$ & 2 & 7 \\
2 & $3(.05)$ & 1 & 3 & $5(.05)$ & 2 & 0 \\
3 & $8(.13)$ & 7 & 4 & $5(.05)$ & 1 & 0 \\
4 & $11(.18)$ & 3 & 3 & $18(.17)$ & 1 & 0 \\
5 & $4(.07)$ & 1 & 0 & $34(.32)$ & 1 & 0 \\
6 & $1(.02)$ & 0 & 0 & $10(.09)$ & 0 & 0 \\
7 & $25(.42)$ & 3 & 4 & $33(.31)$ & 0 & 0 \\
\hline total & $60(1.00)$ & 20 & 20 & $107(1.00)$ & 7 & 7 \\
\hline
\end{tabular}

Figure 8.7. Distribution of individual actions and group minima in weakest-link game experiments.

In Knez and Camerer (1994) we study three-player weakest-link games where players play the game for five periods with the same people. We find that three-player groups also have difficulty playing the weakest-link game efficiently. The distribution of individual actions in the first period, and minimum actions across 20 groups in the first and fifth period of play, are described in Figure 8.7. In both the 3-player and 15-player games, there is significant dispersion in the minimum action selected in the first period of play. This dispersion remains in the fifth period of play in the threeplayer games, and four of the groups reach an efficient minimum of 7 . But in the 14- to 16-player games the minimum action selected in the fifth period is a 1 in every group. (Minima of 1 were also observed by Cachon and Camerer, 1996, for nine-player groups and by Knez and Camerer, 1994, for six-player groups.)

It appears that although small groups of players do not generally play the weakest-link game efficiently (only 4 of 20 reached the efficient outcome of 7), they do a better job of maintaining the level of efficiency achieved in early periods of play than do larger groups.

\subsubsection{The effect of feedback, subject pools, and group expansion}

Five treatments that may be of special interest to organizational researchers have been studied.

Feedback. In most of their sessions, VBB (1990) announced only the minimum action chosen in a group to the group members. An organization 
could announce the entire distribution of actions, and this might improve a group's ability to coordinate on a number higher than 1 . In some sessions, VBB did announce the full distribution, but this did not matter much; if anything, it speeded up the inexorable process of convergence to 1 across trials.

Subject pools. The general pattern of convergence to low-number choices is robust across small variations in subject pools. Besides undergraduates (at Texas A\&M University, the University of Chicago, and the Wharton School), the weakest-link results have been replicated with strategy professors (Knez \& Camerer, 1994) and psychology professors. It would be useful to know whether enhancing group affiliation or organizational identification (e.g., Kramer, 1992) improves coordination.

Group size. Several studies suggest two interesting effects of varying group size in the weakest-link game. First, it is natural to expect that the ability of a group of players to achieve the efficient outcomes increases as group size shrinks, and it does. If the probability that any one of $N$ players will select a small number is equal to $p$, then the probability that a small number is selected by at least one player is $1-(1-p)^{N}$, which increases rapidly as $N$ rises. Second, players do not seem to appreciate how quickly this effect operates because Figure 8.7 shows that the distributions of first-period actions is almost the same in 3-and in 14- to 16-person games. (If anything, the small groups choose lower actions than the larger groups do.) If subjects form vague beliefs over the choices others would make and then compute their optimal response to the distribution of minima in their groups, they should choose much lower numbers when their groups are large. The fact that they do not suggests a kind of "law of small numbers" or representative thinking. Subjects seem to think a low minimum is equally likely in a large group and a small group (see the small- versus largehospital problem in Kahneman \& Tversky, 1972).

Group formation. Knez and Camerer (1994) combined two three-person groups, after five periods of weakest-link play, into a single six-person group. Suppose one group reached a minimum of 4 and the other reached a lower minimum of 2 . Would the combined group achieve a new minimum of 4,2 , or something else? In all 10 combined groups, the new group's minimum was the lower of the previous two minima (a bad norm or expectation drove out a good one). This effect occurred regardless of whether or not each three-person group knew the other group's previous history when they were combined.

Bonus announcements. Knez and Camerer also studied (but did not report) the effect of an announced bonus on performance. First, six-person groups reliably converged to low number minima over several trials ( 7 of 10 groups reached 1). Then the authors announced publicly that each member of a group would receive an extra bonus of 20 or 50 cents if everyone in the group chose a 7. (Notice that a group with a minimum of 1 has an implicit bonus of 60 cents available already, since choosing 7 pays $\$ 1.30$, whereas choosing 1 pays \$.70.) This announcement had a dramatic effect: Eight of 10 groups immediately moved to a minimum of 7 . This result reminds us, as Cooper et al.'s two-way communication showed, how effective a small amount of public communication can be in improving coordination. ${ }^{6}$

\subsubsection{Norms and precedent formation}

The experimental results reported so far all concern the selection of the efficient equilibrium in various coordination games. The results provide powerful evidence that the mere risk that other players in the game will not select the efficient action results in inefficient behavior. In other words, under consistent preferences the mere existence of a Pareto-dominant outcome is not enough to induce efficient outcomes. These results serve as a foundation for the broader study of organizational rules and norms. An organizational rule is, by definition, a rule of behavior that exists prior to the selection of actions by the players in the game. This leaves open the question of how such rules develop and how robust they are to changes in
the structure of the environment.

The traditional approach to norm development (Schein, 1985) assumes the dynamic process described by Homans (1951, p. 127):

Norms do not materialize out of nothing: they emerge from on-going activities. . . . Men bring their norms to a group; they work out new norms through their experience in the group; they take old norms, confirmed or weakened, and the new ones, as developed, to other groups they are members of. If the norms take hold there, a general tradition, the same in many groups, may grow up.

There are two parts to Homans's description of the norm development process. First is the development of norms within subgroups of the organization. Second is the transfer of norms across the subgroups. Hence, an organizational norm or rule arises as previously developed group rules are transferred to new groups over and over again. In order for an organizational rule to develop, this adjustment process must lead to the development in the organization of common beliefs about appropriate modes of behavior in the organization.

At the heart of this adjustment process are precedent effects. The rules that emerge in prior interactions serve as precedents for future interactions. In the language of coordination games, the equilibria selected in previous coordination games serve as precedents for future coordination games.

Research on experimental coordination games has documented the significant role of precedents. Among the most notable examples is the work by VBB (1991) on the median-action game. In this game each player selects a number from the set of integers 1-7. Every player's payoff is higher if the 
median number chosen is higher, and a player's payoff falls if her number is further above or below the median. VBB find strong precedent effects in two forms in groups of 9-27 subjects. First, across all of the experimental treatments, the median action selected in all periods of play was exactly the same as the median action in the first period of play. The precedent set in the first period of play completely determined behavior in later periods. (Cachon \& Camerer, 1996, replicated these results with nine-player groups.) Second, the equilibrium played in previous average opinion games transferred to analogous average opinion games.

Bettenhausen and Murnighan (1985) studied precedent in repeated PDs, most of which had payoffs that make them coordination games. They found strong transfer of cooperative norms across changes in game parameters.

In Knez and Camerer (1995) we document strong precedent effects of two forms. In the experiments reported, subjects played both the weakestlink game in Figure 8.6 repeatedly, as well as two-player and three-player PD games. In one treatment, subjects played all two-player games; in the other treatment, subjects played all three-player games. In both games the efficient outcome has all players selecting the number 7 . In the weakestlink games the efficient outcome is a Nash equilibrium; in the PD games it is not. We were interested in whether a norm of efficiency in the weakestlink game would transfer to the PD game.

In the two-player experiments, under treatment WP subjects played the weakest-link game for five periods and then played the PD game for five periods. Subjects played with the same opponents in all 10 periods of play. Under treatment WP, all five pairs of subjects played the efficient equilibrium in all five periods of play of the weakest-link game. (The fact that all the two-player groups reach efficiency is remarkable because Figure 8.7 shows that only $20 \%$ of three-player groups reach the efficient equilibrium. There appears to be an important leap from two- to three-player groups.) In the subsequent $\mathrm{PD}, 90 \%$ of the subjects who experienced the precedent of efficient play in the weakest-link game selected a 7, the cooperative choice, in the first round of the PD game.

Under treatment PW, subjects played the PD game for five periods and then played the weakest-link game for five periods. In this treatment subjects do not experience the precedent of efficiency before playing the PD (since they play it right away), and only 25\% (5 out of 20 ) of the subjects select a 7 in their first PD game. This difference between the fractions picking efficient 7 's in the WP and PW treatments (90\% versus $25 \%$ ) is highly significant $\left(\mathrm{X}^{2}=11.32, p<.001\right)$. This is a dramatic example of norm transfer.

In the three-player treatments, Knez and Camerer had to take extra steps to get subjects to experience the precedent of efficiency because subjects rarely play the efficient equilibrium in the three-player weakest-link game. In round 1 , four pairs of subjects first played the weakest-link game for five periods. All of these four pairs played the efficient equilibrium (all choosing 7) in all five periods of play. In round 2, one subject was added to the two-player groups from round 1 . All the new players observed the history of play of the two-player groups they were entering, and the round 1 players knew this. Hence, the precedent of efficient play in round 1 was common knowledge in round 2. All four three-player groups played the efficient equilibrium in all five periods of round 2 . These results are in striking contrast to the behavior observed in three-player weakest-link games where subjects had not experienced the precedent of efficient play in the two-player games.

Finally, when players start out in three-player groups a precedent of inefficient play in the weakest-link game develops, but when they start out in two-player groups the precedent of efficiency develops. Again, we found a strong and significant precedent effect. Under the precedent of efficiency, $73 \%$ of the subjects select a 7 in the first period of the threeplayer PD game, whereas under the inefficient precedent only $22 \%$ select a $7\left(X^{2}=8.62, p<.004\right)$.

In summary, Knez and Camerer (1995) found that the precedent of efficiency transfers from the weakest-link game to the PD game in both twoplayer and three-player groups. They also found that efficient behavior can be induced in three-player weakest-link games by first allowing players to develop the home-grown precedent of efficient play in the two-player weakest-link game. (We conjecture that one can develop efficient groups of any size in the weakest-link game this way by letting $n$-person groups play long enough to establish a firm history of efficient play of choosing 7 's, letting newcomers know about this history, and adding only two or three players at a time.)

8.6.5 A digression on economic and psychological experimental methods

Most readers of this book are probably familiar with the experimental paradigm followed by organizational psychologists and relatively unfamiliar with (or even hostile to) the methods experimental economists use (e.g., Davis \& Holt, 1992). For example, the experiments we just described may seem overly simple and devoid of context. We think the design differences in the two approaches spring largely, and defensibly, from basic differences in how knowledge is compiled in economics and psychology. We summarize this argument briefly (see Camerer, in press).

The purpose of most economics experiments is to clearly operationalize a setting in which a theory makes a clear prediction. As a direct result of this goal, to study assurance games it is essential to create a situation in which $(\mathrm{L}, \mathrm{L})$ and $(\mathrm{H}, \mathrm{H})$ are both equilibria and $(\mathrm{H}, \mathrm{H})$ is better for everyone but riskier. If we cannot be sure that these conditions are met, then the game-theoretic predictions are not being tested and nothing is contributed to economic knowledge. To meet these conditions, the experiment uses an 
abstract, a-realistic context (subjects choose numbers or letters). Subjects are also paid substantial financial incentives to help ensure that they really do prefer $(H, H)$ to $(L, L)$. The key design elements - abstract context and financial incentives - fit together to achieve the main purpose, which is to operationalize a setting about which game theory makes a prediction.

The purpose of psychology experiments ${ }^{7}$ is generally to express an informal intuition or regularity in a dramatic, lifelike way or yield data with which to construct a new theory. Because subjects are often unpaid (e.g., participating for course credit), an abstract task might bore or confuse them, so a concrete one is better. Because their purpose is different from the theory-testing motive of economists, psychologists might study coordination differently.

For example, we could ask two subjects to perform a mildly aversive task, like pedaling a bicycle at either of two programmed rates, slow or fast, and pay them each a larger prize if they both pedal fast. (Tasks like this were used in early "social loafing" experiments; see Kidwell \& Bennett, 1993.) Simultaneous pedaling resembles an assurance game, but we cannot be sure it is. It is not an assurance game if either subject is fanatic enough about exercise to simply prefer pedaling faster; then (fast) is a dominant strategy so (slow,slow) is not an equilibrium. It is also not an assurance game if one subject (or both) dislikes pedaling so much that he would rather forego his prize than match the other player's fast pedaling; then (slow) is a dominant strategy and (fast,fast) is not an equilibrium. So to be sure that pedaling is really an assurance game, we must be sure that both players do not like pedaling too much or like it too little (and also be sure that players know this about others) or else control these preferences and beliefs. ${ }^{8}$ One way to control them is to use an abstract task like choosing letters or numbers and pay financial rewards, as in Figure 8.2.

The advantage of a task like pedaling is its improvement in realism, external validity, or generalizability to organizations (compared to abstract number choosing for money). But this apparent improvement can be reasonably disputed on two grounds.

First, judgments of external validity should be grounded in a statistical understanding of what organizational situations are common. Are pedaling-like tasks really more common than choosing abstract symbols that yield monetary rewards? The answer is hard to know. Consider a law firm. Attorneys on a litigation team who spend long hours in court, exerting fatiguing effort, may be like subjects pedaling bikes. But other lawyers research legal details in a library or compile abstract symbols into briefs; perhaps their work is more like choosing letters that yield financial payoffs than like bike pedaling.

Second, it is unclear that experiments should be like a random sample of realistic organizational situations. Scientists routinely oversample unusual situations (neglecting mundane ones). Neuroscientists study victims of unusual traumas, biologists study strange species, economists study de- pressions and market crashes, and astronomers study supernovas. These phenomena are all rare and hence highly unrealistic, but they provide an efficient way to learn about general processes. While hesitating to claim the same status for the simple experiments described previously, we simply want to question (1) how to determine which experiments are most realistic and (2) whether realism is desirable.

A final thought about context: Economic experiments are happily unrealistic because economics and game theory make no special predictions about behavior in more or less realistic situations. (If the purpose of the experiment is theory testing, the experiments need only be as realistic as the theory.) This does not mean that game theorists insist that context does not matter to outcomes. It simply means that there is no systematic theory of precisely how context matters. Obviously, one way to build up such a theory is to start with context-free baseline experiments (like the $2 \times 2$ results described earlier) and then experiment incrementally with contextual changes (like one- and two-way communication). Further changes of organizational interest can be added easily.

\subsection{Conclusion}

We began the chapter by pointing out three kinds of coordination problems in firms. Matching problems occur when players agree on what is the best outcome for the organization (and for themselves) but, for one reason or another, cannot necessarily achieve it. Mixed-motive bargaining problems occur when players would like to strike some mutually agreeable deal (rather than cause an impasse) but different players prefer different deals. Assurance problems occur when players agree on what is best but actions that lead to the best outcome are riskier, so players want to take them only if others probably will as well.

We then introduced a simple class of games from noncooperative game theory, known as coordination games, which precisely operationalize these three coordination problems. We contrasted these games with the PD and argued that the conditions for true PDs are rarely met in actual organizations; instead, those games are coordination games.

Next, we elaborated on the point that the application of simple coordination games to organizational coordination problems focuses attention on mechanisms that transform expectations rather than mechanisms that transform preferences. We refer to such expectations as organizational expectations, which are loosely defined as the mutual beliefs by all members of an organization that all members will follow a particular rule or norm. We argued that this mutual-belief condition is at the foundation of organizational rules and norms. Hence, understanding the factors that govern the structure and development of mutual beliefs will provide important insights into organizational rules and norms. 
We concluded by describing experimental research on coordination games, which represents the first steps in examining the behavioral underoxpectations. This experimental research documents that risky coordination does indeed lead to inefficient behavior. In ther words, despite the simplicity of these games, subjects are not able to intuit (or are unwilling to bet that others have intuited) the rule of efficient ay subject understands that 7 in the weakest-link game is the right action, but they are not sufficiently confident that all other subjects underthand this too. We are presently exploring the impact of many variants of this game. Our goal is to understand the conditions necessary for such a is the mutual knowledge required to select rule provision in order to

the efficient equilibrium.

We also highlighted experimental research that docume, as well as transcedent effects across trials of the same coordination game, We see these fer of precedents from coordination games to results as first steps in using these simple coordinations and norms.

the development and transfer of organizational rules and as a system for

Our most basic claim is that game theory is usefule might behave classifying organizational situations, analyzing how people might behave in them, and making clear predictions that can be think of a decision a with more work, in the field. Indeed, it is hard to think of a decine (in the person makes inside an organization that is not a strategy in a gayoff from a sense that the choices others make at the same time affect the payoff from certain decision).

In future work, we hope to apply the PD-coordination distinction to highlight the difference between a coordination perspective and the Williamsonian theory of the firm, which focuses on "holdup" problems that are eliminated by integration. We also think that some anomalous features of faddish business practices (like total quality management and reengineering) can be thought of as solutions to the problem of coordinating organizational change (see Camerer \& Knez, in press).

\section{Notes} 1 This example does not require aversion, either for sheer pleasure, to impress a they both prefer to deliver the order, either for well.

supervisor, or in the expectation of being tipped whedge. Aumann and Branden-

2 Our discussion is a simplification of mutual knowtions for the existence of a pure burger (1995) show that the two necessary conditions for the expl mutual knowlstrategy Nash equilibrium are muledge of beliefs means that each player knows the edge of rationality. Mutual knowledge of beliefs means that each that each player other player's beliefs. Mutual knowledge of rationality maximizes her expected knows that the other player selects the action that maximizes her expectedpayoff given her beliefs. We focus on the mutual knowledge of belition.
3 An outcome is Pareto efficient if there is no alternative outcome for which one player is made better off without making another player worse off. The most notable example is cooperation in the PD. But note that although cooperation in the (single-play) PD is Pareto efficient, it is not a Nash equilibrium.

4 Cobb-Douglas production functions, commonly used in econometric studies of labor-capital productivity, exhibit this property for extreme parameter values. Cornes (1993) shows that if $q_{i}$ are $n$ separate inputs, the function $Q=a\left[(1 / n)\left(q_{1}{ }^{v}\right.\right.$ $\left.\left.+q_{2}^{v}+\ldots q_{n}^{v}\right)\right]^{1 / v}$ exhibits precisely the weakest-link structure as $v$ grows large and negative, and includes other interesting structures as alternative special cases (see also Hirshleifer 1983). Jacobs (1981) presents a sociological discussion of weak-link production in organizations.

5 Restricting actions to picking numbers seems highly artificial. But the numbers are not essential; they are simply used to label equilibrium outcomes from best (for everyone) to worst. Any set of nonnumerical choices that yields Paretorankable outcomes could be used as well. For example, the actions could represent seven different methods of restructuring (or acquisition targets, strategic alliances, etc.) labeled A through $\mathrm{G}$. Suppose $\mathrm{A}$ is more valuable than B, B than alliances, etc.) labeled $A$ through $G$. Suppose $A$ is more valuable than $B$, $B$, forth, if incumbent managers allocate scarce resources and energy to making restructuring A work. And suppose they prefer to do so if other managers will, but they do not want to invest in $C$, say, if some other manager will only invest in $\mathrm{E}$. Then they play a weakest-link game that is formally equivalent to the game we study. The actions are numbered just to denote which methods are best.

6 Hypersensitivity to communication raises an important methodological concern: Because communicating with members is one thing most organizations can do well, why study a class of problems that would be so easily solved by real organizations through communication? Our answer is that we think genuine coordination problems involve some combination of other features, deliberately coordination problems involve some combination of othericult even with communication. For example, effective communication may have to be public, and with most members present. Also, large coordination problems with thousands of most members present. Also, large coordination problems with thousands of may be harder to solve with limited communication. Finally, the same criticism about hypersensitivity to communication can be leveled at many studies of PDs, because we know that some kinds of communication improve cooperation substantially (Sally, 1995).

7 Here we have in mind the kinds of experiments conducted by psychologists most likely to be interested in coordination, namely, social psychologists. Other subfields work differently. Perceptual and cognitive psychology, for example, use much simpler stimuli to get at basic cognitive processes and resemble the experimental economics style.

8 Preferences and beliefs about pedaling could be measured independently of the assurance task, but that might require inefficiently discarding many subjects before recruiting enough who are not too exercise crazy or averse. Or beliefs could be created through the use of deception or confederate subjects, but deception can be objected to on other grounds (see Camerer, in press). For example, if the beliefs being induced - say, that Californian subjects do not like pedaling too much - are unlikely to arise naturally and so must be induced through deception, then one must wonder whether subjects believe the decep- 
tion. Experimental economists also worry about long-run harm to experimenter credibility from repeated deception.

\section{References}

Akerlof, G., \& Yellen, J. (1990). The fair wage-effort hypothesis and unemployment. Quarterly Journal of Economics, 105, 255-283.

Aumann, R. (1985). What is game theory trying to accomplish? In K. J. Arrow \& S. Honkapohja (Eds.), Frontiers of economics (pp. 28-76). Oxford: Basil Blackwell.

Aumann, R., \& Bradenburger, A. (1995). Epistemic conditions for Nash equilibrium. Econometrica, 63, 1161-1180.

Barnard, C. (1938). The functions of the executive. Cambridge, MA: Harvard University Press.

Becker, G. S., \& Murphy, K. J. (1992). The division of labor and coordination. Quarterly Journal of Economics, 107, 1137-1160.

Bettenhausen, K., \& Murnighan, J. (1985). The emergence of norms in competitive decision-making groups. Administrative Science Quarterly, 30, 350-372.

Cachon, G., \& Camerer, C. F. (1996). Loss-avoidance and forward induction in experimental coordination games. Quarterly Journal of Economics, 110, 165194.

Camerer, C. F. (in press). Rules for experimenting in psychology and economics, and why they differ. In W. Güth \& E. Van Damme (Eds.), Essays in honor of Reinhard Selten, Springer-Verlag.

Camerer, C. F., \& Knez, M. (in press). Coordination, organizational boundaries, and fads in business practice. Industrial and Corporate Change.

Chisholm, D. (1989). Coordination without hierarchy: Informal structures in multiorganizational systems. Berkeley: University of California Press.

Cooper, R., DeJong, D. V., Forsythe, R., \& Ross, T. W. (1989). Selection criteria in coordination games. American Economic Review, 80, 218-233.

Cooper, R., Dejong, D., Forsythe, R., \& Ross, T. (1992). Communication in coordination games. Quarterly Journal of Economics, 107, 739-771.

Cooper, R., Dejong, D., Forsythe, R., \& Ross, T. (1994). Alternative institutions for resolving coordination problems: Experimental evidence on forward induction and preplay communication. In J. Friedman (Ed.), Problems of coordination in economic activity (pp. 129-146). Norwell, MA: Kluwer.

Cooper, R., \& John, A. (1988). Coordinating coordination failures in Keynesian models. Quarterly Journal of Economics, 103, 441-464.

Cornes, R. (1993). Dyke maintenance and other stories: Some neglected types of public goods. Quarterly Journal of Economics, 108, 259-272.

Davis, D., \& Holt, C. (1992). Experimental economics. Princeton, NJ: Princeton University Press.

Gibbons, R. (1992). Game theory for applied economists. Princeton, NJ: Princeton University Press.

Gibbons, R. (in press). Game theory and garbage cans. In J. Halpern \& R. Stern (Eds.), Nonrational decision making in organizations. Ithaca, NY: ILR Press, Cornell University.

Harsanyi, J., \& Selten, R. (1988). A general theory of equilibrium selection in games. Cambridge, MA: MTT Press. Hirshleifer, J. (1983). From weakest-link to best-shot: The voluntary provision of
public goods. Public Choice, 41, 371-386.

Jomans, G. (1951). The human group. New Brunswick, NJ: Transaction. inquiry into the consequeory of mobility and behavior in organizations: An mance and organizational success. American loums between individual perfor-

Kahneman, D., \& Tversky, A. (1972). Subjerican Journal of Sociology, 87, 684-707. sentativeness. Cognitive Psychology, 3, 430-454.

Kanodia, C., Bushmog

cost effect: An explanation based, J. (1989). Escalation errors and the sunk ries. Journal of Accounting Research, 27,59-77.

Keenan I \& Wilson, R. (1990). Research, 27, 59-77. 1128.

conceptual model to intersect (1993). Employee propensity to withhold effort: A ment Review, 18, 429-456.

Coordination in " C. (1994). Creating expectational assets in the laboratory: 119. games. Working paper, University transfer in coordination and social dilemmo

Kramer, R. (1990). Multi-party niversity of Chicago Graduate School of Business. organizations: Social py negotiation and the "tragedy of the commons" in B. Shepard, \& M. psychological aspects of strategic choice. In R. Lewicki, (Vol. 3). Greenwich, CT: JAI Press.

(Ed.), Social psycholoty in and organizational/identification. In K. Murnighan Prentice-Hall.

\section{Lamoreaux, $\mathrm{N}$, \&}

on the organization D. (1995). Coordination and information: Historical perspectives

Ledyard, J. (1995). Public goods. In J. Kagel University of Chicago Press. tal economics (pp. 111-194). Pringel \& A. Roth (Eds.), Handbook of experimen194. tion formation in organizations.
tion Processes, 51, 198-219

March,

Marschak, J., \& Radner. (1958). Organizations. New York: Wiley. University Press.
. 1972). Economic theory of teams. New Haven, CT: Yale

grom, P., \& Roberts, J. (1992). Economics, organization, and management. En-
glewood Cliff, NJ. Prontice

Miller

Cambridge University Press.

Mooney, J. (1947) Principles Press.

Murnighan, J. K. (1994). Game theory in. New York: Harper \& Brothers.

Cummings (Eds.), Research in Organizational Behavior behavior. In B. Staw \& L. Greenwich, CT: JAI Press.

York: Free Press.
Y. (1991). Cognition and rationality in negotiations. New 
Orbell, J., van de Kragt, A., \& Dawes, R. (1988). Explaining discussion-induced cooperation. Journal of Personality and Social Psychology, 54, 811-819.

Organ, D. W. (1988). Organizational citizenship behavior: The good soldier syndrome. Lexington, MA: Heath.

Porac, J., Thomas, H., \& Emme, B. (1987). Knowing the competition: The mental models of retailing strategists. In G. Johnson (Ed.), Business strategy and retailing (pp. 59-79). New York: Wiley.

Prendergast, C. (1993). A theory of "yes men." American Economic Review, 83, 757770 .

Rabin, M. (1993). Incorporating fairness into game theory and economics. American Economic Review, 83, 1281-1302.

Rapoport, Am. (1987). Research paradigms and expected utility models for the provision of step-level public goods. Psychological Review, 94, 74-83.

Rapoport, Am., \& Guyer, M. (1976). The $2 \times 2$ game. Ann Arbor: University of Michigan Press.

Rousseau, D., \& Parks, J. (1992). The contracts of individuals and organizations. In L. Cummings \& B. Staw (Eds.), Research in organizational behavior (Vol. 15, pp. 1-43). Greenwich, CT: JAI Press.

Rumelt, R. (1995). Inertia and transformation. In C. Montgomery (Ed.), Resourcebased and evolutionary theories of the firm: Towards a synthesis (pp. 101-132). Norwell MA: Kluwer.

Sally, D. (1995), On sympathy. Working paper, Cornell University Johnson Graduate School of Management.

Scharfstein, D., \& Stein, J. (1990). Herd behavior and investment. American Economic Review, 80, 465-479.

Schein, E. (1985), Organizational culture and leadership. San Francisco: Jossey-Bass.

Schelling, T. (1960). The strategy of conflict. Cambridge, MA: Harvard University Press.

Stanford, W. (1995). A note on the probability of $k$ pure Nash equilibria in matrix games. Games and Economic Behavior, 9, 238-246.

Thompson, J. D. (1967). Organizations in action. New York: McGraw-Hill.

Van Huyck, J. B., Battalio, R. B., \& Beil, R. O. (1990). Tacit coordination games, strategic uncertainty, and coordination failure. American Economic Review, 80, 234-248.

Van Huyck, J. B., Battalio, R. B., \& Beil, R. O. (1991). Strategic uncertainty, equilibrium selection principles, and coordination failure in average opinion games. The Quarterly Journal of Economics, 106, 885-910.

Zajac, E., \& Bazerman, M. (1991). Blind spots in industry and competitor analysis: Implications of interfirm (mis)perceptions for strategic decisions. Academy of Management Review, 16, 37-56.

\section{Part IV \\ Decision processes}

